Humanized Computing and Communication

Vol. 2, No. 1 (2021) 20-45

(C) KS Press, Institute for Semantic Computing Foundation

DOI: $10.35708 / \mathrm{HCC} 1869-148366$

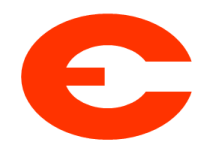

\title{
A Conceptual Framework for Machine Self-Presentation and Trust
}

\author{
Jeff Stanley $^{1}$, Ozgur Eris ${ }^{1}$, and Monika Lohani ${ }^{2}$ \\ 1 The MITRE Corporation at 7525 Colshire Dr, McLean, VA, USA \\ \{jstanley, oeris\}@mitre.org \\ 2 The University of Utah at 201 Presidents' Cir, Salt Lake City, UT, USA \\ Monika.Lohani@utah.edu
}

Received $(12 / 15 / 2020)$

Revised (01/30/2021)

Accepted (02/16/2021)

\begin{abstract}
Increasingly, researchers are creating machines with humanlike social behaviors to elicit desired human responses such as trust and engagement, but a systematic characterization and categorization of such behaviors and their demonstrated effects is missing. This paper proposes a taxonomy of machine behavior based on what has been experimented with and documented in the literature to date. We argue that selfpresentation theory, a psychosocial model of human interaction, provides a principled framework to structure existing knowledge in this domain and guide future research and development. We leverage a foundational human self-presentation taxonomy (Jones and Pittman, 1982), which associates human verbal behaviors with strategies, to guide the literature review of human-machine interaction studies we present in this paper. In our review, we identified 36 studies that have examined human-machine interactions with behaviors corresponding to strategies from the taxonomy. We analyzed frequently and infrequently used strategies to identify patterns and gaps, which led to the adaptation of Jones and Pittman's human self-presentation taxonomy to a machine self-presentation taxonomy. The adapted taxonomy identifies strategies and behaviors machines can employ when presenting themselves to humans in order to elicit desired human responses and attitudes. Drawing from models of human trust we discuss how to apply the taxonomy to affect perceived machine trustworthiness.
\end{abstract}

Keywords: self-presentation; impression management; embodied agents; social machines; emotional intelligence. 


\section{Introduction}

Machines embedded with social behaviors elicit predictable social responses from humans. Nass et al. (1994) introduced the "Computers are Social Actors" hypothesis that humans respond to machines with humanlike behaviors the same way they would respond to humans [78. Since then, drawing from experimentation with human-to-human interaction, additional studies have demonstrated the ability of socially intelligent machines to calibrate human trust and compliance, increase liking and engagement, reduce stress, and improve task performance (e.g. 62, 22, 16, 19, 14,63 ). However, it is difficult to systematically compare and integrate lessons learned across parallel research efforts due to the lack of an underlying framework for classifying social machine behavior. In this paper, we argue that the influential self-presentation theory [36] provides a principled foundation to structure existing knowledge and guide future research and development in the human-machine interaction domain. By categorizing these studies according to a self-presentation taxonomy, we can integrate and draw conclusions across different studies.

Building on that position, our overarching research goals are to (1) categorize studies on how socially intelligent machines interact with humans according to a self-presentation taxonomy, (2) integrate the empirical findings of those studies based on the categories, and (3) identify strategies that have received limited attention but may be relevant for future research directions.

In this paper, we approach our first goal by briefly introducing self-presentation theory and discussing its relevance to human-machine interaction.

Inspired by Erving Goffman's "Presentation of the Self in Everyday Life" 24], Jones and Pittman identified five strategies humans use in order to enhance the image they present to others (Table 1). The human employing the strategy is known as the actor, and the intended audience of the presentation is called the target. Each strategy is intended to promote a different perceived trait. For example, to look more competent during a job interview, the actor may employ a strategy of Self-promotion, emphasizing her credentials and achievements and taking credit for past successful efforts. On the other hand, an employee seeking advancement might dress formally and work late hours not because it demonstrates competence but because it demonstrates integrity and commitment to the principles of the work environment, which aligns with the Exemplification strategy. Employing the Ingratiation strategy makes the actor appear to like the target by flattering, agreeing, doing favors, and otherwise showing esteem; thereby securing reciprocal liking from the target. An actor employing the Intimidation strategy seeks compliance by appearing dangerous, while an actor employing the Supplication strategy appears helpless in order to invoke the target's nurturing instinct and sense of social obligation. 
Table 1. Self-presentation strategies after [36, and some of their measured effects with sources. Some sources address more than one strategy.

\begin{tabular}{|c|c|c|c|c|c|}
\hline Strategy & $\begin{array}{l}\text { Promoted } \\
\text { trait }\end{array}$ & Strategy definition & Prototypical behaviors & $\begin{array}{l}\text { Measured effects on tar- } \\
\text { get }\end{array}$ & \begin{tabular}{|l|} 
Example \\
sources
\end{tabular} \\
\hline Exemplification & integrity & $\begin{array}{l}\text { Emphasizing } \text { actor's } \\
\text { adherence to princi- } \\
\text { ples. }\end{array}$ & $\begin{array}{lr}\text { Conspicuously } & \text { showing } \\
\text { self-discipline, } & \text { making } \\
\text { demonstrations } & \text { and } \\
\text { justifications for } & \text { a cause }\end{array}$ & $\begin{array}{l}\text { Increased perceived in- } \\
\text { tegrity and leadership po- } \\
\text { tential of actor, team co- } \\
\text { hesion, commitment to } \\
\text { task }\end{array}$ & \begin{tabular}{|l|l|}
20 & \\
66 & 9 \\
83 & 17 \\
\end{tabular} \\
\hline Ingratiation & friendliness & $\begin{array}{l}\text { Expressing apprecia- } \\
\text { tion or commitment } \\
\text { to the target. }\end{array}$ & $\begin{array}{l}\text { Disclosing sensitive per- } \\
\text { sonal information, agree- } \\
\text { ing with opinions, show- } \\
\text { ing a personal interest }\end{array}$ & $\begin{array}{l}\text { Increased liking of, favors } \\
\text { for, and trust in actor }\end{array}$ & \begin{tabular}{|l|l|}
88 & 10 \\
104 & 91 \\
\end{tabular} \\
\hline Intimidation & danger & $\begin{array}{l}\text { Suggesting the actor } \\
\text { could cause difficul- } \\
\text { ties for the target. }\end{array}$ & $\begin{array}{l}\text { Making threats, acting } \\
\text { volatile, creating discom- } \\
\text { fort }\end{array}$ & $\begin{array}{l}\text { Increased compliance to- } \\
\text { ward actor }\end{array}$ & 38 \\
\hline Self-promotion & competence & $\begin{array}{l}\text { Emphasizing actor's } \\
\text { strengths. }\end{array}$ & $\begin{array}{l}\text { Claiming responsibility } \\
\text { for a good outcome, high- } \\
\text { lighting strengths and } \\
\text { achievements, showing } \\
\text { off }\end{array}$ & $\begin{array}{l}\text { Increased perceived com- } \\
\text { petence and leadership } \\
\text { potential of actor, compli- } \\
\text { ance toward actor }\end{array}$ & \begin{tabular}{|l|l|}
66 & 43 \\
82 & \\
\end{tabular} \\
\hline Supplication & dependence & $\begin{array}{l}\text { Emphasizing actor's } \\
\text { vulnerability to elicit } \\
\text { sympathy or obliga- } \\
\text { tion. }\end{array}$ & $\begin{array}{l}\text { Appearing weak or needy, } \\
\text { asking for help }\end{array}$ & $\begin{array}{l}\text { Increased support to and } \\
\text { engagement with actor }\end{array}$ & 106 85 \\
\hline
\end{tabular}

Many human-machine interaction studies implicitly make use of these strategies ${ }^{3}$ For instance, in one of the studies reviewed as part of this research, humans were more willing to respond to computer prompts if that computer had helped them with a web search previously [41]; doing favors is an Ingratiation behavior. In another case, a robot that advertised its medical functions was more accepted by potential human patients than one that did not [44]; highlighting one's strengths is a Self-promotion behavior. Therefore, the self-presentation taxonomy allows us to integrate and draw conclusions across different studies. For example, studies exploring machine self-disclosure, empathy, flattery, and humor fall under the self-presentation strategy of Ingratiation, which targets human attitudes including liking, trust, willingness to do reciprocal favors for, and perceived friendliness.

\section{Materials and Methods}

We performed a literature review to identify machine behaviors corresponding with self-presentation strategies. The literature search was carried out by per-

${ }^{3}$ [14 is the only human-machine interaction study we found that explicitly references self-presentation strategies. 
forming online keyword searches in Google Scholar and by following citations and references from one publication to another, assisted by Google Scholar, ACM Digital Library, IEEE Xplore, APA PsycNET, ScienceDirect, and arXiv.org. Search terms included variations of "computer", "agent", "robot", and "machine", combined with "self-presentation" and "impression management". Other search terms included particular self-presentation strategies and associated behaviors, such as "flattery", "empathy", "self-disclosure", "self-promotion", and "intimidation". For thoroughness we also considered relevant studies already known or recommended to us. We selected papers using the following inclusion criteria:

1. The publication had been peer-reviewed.

2. The study had adequate controls that would allow for effects to be measured with confidence. This criterion excluded non-experimental sources such as case studies.

3. The dependent variables of the study are the responses of humans interacting with a machine such as a computer, virtual agent, or robot.

4. The independent variables of the study include the verbal behavior of the machine. The self-presentation literature has neglected nonverbal behaviors like gestures and facial expressions, mainly because they are hard for humans to consciously control [13]. However, we address the implications of this taxonomy for nonverbal machine behavior in our discussion.

We reviewed 105 studies, of which 71 provided evidence on the effects of machine behavior on human attitudes and 42 manipulated the verbal behavior of the machine. We identified machine behaviors from the reviewed studies that correspond with the self-presentation taxonomy. These machine behaviors were classified according to the self-presentation strategies and analyzed for patterns.

\section{Results}

The survey found 36 studies that describe verbal machine behaviors corresponding to strategies in the Jones and Pittman taxonomy (see appendix), 4 Of the 36 studies, over three quarters $(28 / 36$ or $76 \%)$ examined Ingratiation behaviors showing esteem for the human such as flattery, disclosure, playfulness, and empathy. Seven of the studies used Supplication behaviors to elicit human sympathy such as appearing weak, asking for help, and making errors and apologies. Four of the machines in the studies used Exemplification behaviors, showing serious dedication to a task, giving motivational messages, and referencing charitable activities. Two machines used Self-promotion to make themselves appear more competent. No machines were implemented with behaviors to intimidate their partners. The numbers total more than 36 because some studies included behaviors corresponding with more than one strategy.

\footnotetext{
${ }^{4}$ Examples of verbal behaviors not accounted for by the self-presentation taxonomy are: appearing introverted or extroverted [55, clarifying roles and procedures [62, polite language [107, and unexpected or inappropriate utterances [50].
} 


\section{Discussion}

\subsection{A Self-Presentation Taxonomy for Machines}

The distribution of studies across the self-presentation taxonomy reveals patterns in human-machine research that highlight current research focus and suggest future directions. We examine each strategy below (subsections 4.2-4.6). Our analysis demonstrates that humans respond to machine behavior as they would to human behavior as predicted by self-presentation (see Tables 1 and 2). Our analysis also leads us to identify Self-effacement as a relevant machine self-presentation strategy (subsection 4.7). After a discussion of nonverbal behaviors (subsection 4.8), we propose a new self-presentation strategy unique to machines, Personification (subsection 4.9). The result is an extension of the human self-presentation taxonomy to a self-presentation taxonomy for machines (Table 2). To illustrate the potential of this new taxonomy we discuss its application to one common problem in human-machine interaction studies: human trust in machines (subsection 4.10). We end with a note about cross-cultural implications (subsection 4.11).

\subsection{Exemplification}

Machine Exemplification - demonstrating commitment to a task, cause, or principle - is underrepresented in the literature (four out of 36 studies of machine behavior corresponding with self-presentation strategies). Given the ongoing concern with "machine morality" as machines are given more autonomy over their tasks and the impact this has on human trust [68], this lacuna is surprising. Four studies explored Exemplification behaviors and are described below: offering motivational messages, encouraging the human to be involved in a task, and associating with good deeds. Machine Exemplification elicits reciprocal commitment and dedication from human partners, as anticipated by human Exemplification studies.

In one study, students in a computer literacy course were assigned one of twelve different digital tutors and asked to develop instructional plans. The students whose pedagogical agents offered motivational messages worked more carefully and thoughtfully than the others 3 .

In two cases 223, a robot that acted with formal politeness and focused on the task at hand (Exemplifying) was contrasted to a robot employing playful (Ingratiating) behaviors. The Exemplifying robot increased commitment to a goal, while the Ingratiating robot increased enjoyment and liking.

Exemplification may also impact trust. An agent that presented itself as helping people in need was perceived as more trustworthy than agents presenting themselves as serving a medical team or the government [108. This is in line with research connecting perceived integrity to trust [70] and demonstrates the potential of Exemplification behaviors for improving trust in machines.

Mobile health apps implement behaviors that might be considered Exemplification behaviors such as setting and reviewing goals, rating the user, and comparing the user to others [11, in the sense that they show commitment to 
desirable norms and values. Malle 68] described how a machine could demonstrate integrity by maintaining and communicating desirable norms and values.

Based on human Exemplification research, we expect that machine Exemplification would raise moral and leadership expectation [20] 66] [9]. The studies we surveyed did not measure these outcomes.

Table 2. A self-presentation taxonomy for machines. This table only lists a few representative sources. A full listing is found in the appendix.

\begin{tabular}{|c|c|c|c|c|c|}
\hline Strategy & $\begin{array}{l}\text { Promoted } \\
\text { trait }\end{array}$ & Strategy definition & $\begin{array}{l}\text { Behaviors in the litera- } \\
\text { ture }\end{array}$ & $\begin{array}{l}\text { Measured effects on tar- } \\
\text { get }\end{array}$ & $\begin{array}{l}\text { Example } \\
\text { sources }\end{array}$ \\
\hline Exemplification & integrity & $\begin{array}{l}\text { Emphasizing actor's } \\
\text { adherence to princi- } \\
\text { ples. }\end{array}$ & $\begin{array}{l}\text { Showing commitment to } \\
\text { a task, good works, in- } \\
\text { spiring messages }\end{array}$ & $\begin{array}{l}\text { Increased trust in ma- } \\
\text { chine and commitment to } \\
\text { task }\end{array}$ & 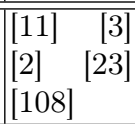 \\
\hline Ingratiation & friendliness & $\begin{array}{l}\text { Expressing apprecia- } \\
\text { tion or commitment } \\
\text { to the target. }\end{array}$ & $\begin{array}{l}\text { Self-disclosure, empathy, } \\
\text { flattery, doing favors }\end{array}$ & $\begin{array}{l}\text { Increased liking of, per- } \\
\text { ceived friendliness of, and } \\
\text { trust in machine, and re- } \\
\text { ciprocal favors }\end{array}$ & \begin{tabular}{|ll}
30 & 35 \\
47 & 52 \\
59 & \\
59
\end{tabular} \\
\hline Intimidation & danger & $\begin{array}{l}\text { Suggesting the actor } \\
\text { could cause difficul- } \\
\text { ties for the target. }\end{array}$ & $\begin{array}{l}\text { No machine examples } \\
\text { found }\end{array}$ & & \\
\hline Self-promotion & competence & $\begin{array}{l}\text { Emphasizing actor's } \\
\text { strengths. }\end{array}$ & $\begin{array}{l}\text { Explaining qualifications, } \\
\text { looking and sounding like } \\
\text { an expert }\end{array}$ & $\begin{array}{l}\text { Increased perceived com- } \\
\text { petence and trust in ma- } \\
\text { chine }\end{array}$ & \begin{tabular}{|lll}
14 & 44 \\
\end{tabular} \\
\hline Supplication & dependence & $\begin{array}{l}\text { Emphasizing actor's } \\
\text { vulnerability to elicit } \\
\text { sympathy or obliga- } \\
\text { tion. }\end{array}$ & $\begin{array}{l}\text { Looking "cute", needing } \\
\text { care, playing dumb, ask- } \\
\text { ing for help }\end{array}$ & $\begin{array}{l}\text { Increased support to and } \\
\text { engagement with machine }\end{array}$ & \begin{tabular}{|l|}
1 \\
95 \\
\end{tabular} \\
\hline $\begin{array}{l}\text { Self-effacement } \\
\text { (added) }\end{array}$ & humility & $\begin{array}{l}\text { Downplaying actor's } \\
\text { strengths to be relat- } \\
\text { able. }\end{array}$ & $\begin{array}{l}\text { Making and recovering } \\
\text { from minor errors, apolo- } \\
\text { gies }\end{array}$ & $\begin{array}{l}\text { Increased liking and ac- } \\
\text { ceptance but lower per- } \\
\text { ceived competence of ma- } \\
\text { chine }\end{array}$ & \begin{tabular}{|ll}
50 & 27 \\
73 & \\
\end{tabular} \\
\hline $\begin{array}{l}\text { Personification } \\
\text { (proposed) }\end{array}$ & alive-ness & $\begin{array}{l}\text { Appearing to be a } \\
\text { "real" person. }\end{array}$ & $\begin{array}{l}\text { Mimicking human at- } \\
\text { tributes, appearance, and } \\
\text { behavior. }\end{array}$ & $\begin{array}{l}\text { Increased trust in ma- } \\
\text { chine }\end{array}$ & \begin{tabular}{|l|l|}
32 & 103 \\
99
\end{tabular} \\
\hline
\end{tabular}

\subsection{Ingratiation}

Recent human-machine studies clearly favor a strategy of Ingratiation (28 out of 36 studies) - that is, acting friendly. Common Ingratiation behaviors in the human-machine literature are flattery, showing empathy, and self-disclosure. The effects of Ingratiation include improved liking, trust, and perceived friendliness, as anticipated by human Ingratiation studies.

In one typical example, a digital blackjack opponent was programmed to display text that was either self-centered ("The dealer beat me; I'm disappointed") 
or empathic ("You won; that's wonderful!"). The empathic agent was rated as more caring, supportive, likeable and trustworthy [8]. Similar results have been noted for machines that are agreeable and that use flattery, humor, and selfdisclosure.

Another common reaction to machine Ingratiation is reciprocal benevolent behavior, particularly in the case of favors, agreement, and self-disclosure [41] [94] 39].

\subsection{Intimidation}

No examples of machine Intimidation were found. Evidently, scholars have been more interested in crafting friendly machines (through Ingratiation) than scary machines (through Intimidation). People who are "intimidated" by their nonhuman teammates sometimes fail to speak up to correct errors and prevent loss [33. p. 334], which can lead to tragic loss of life in the case of aircraft, ground vehicles, and weapons systems. However, there are reasons to explore machine Intimidation. It may be desirable for a machine to appear intimidating to an adversary for defense applications (e.g., national security, home safety, and personal protection). Intimidation may prevent costly engagements; pirates in the 18th century had such a dangerous reputation that the sight of the Jolly Roger could elicit quick surrender from merchant ships [58]. Intimidation may also help to discourage misbehavior, such as in the case of robots monitoring students for cheating [77].

\subsection{Self-Promotion}

Examples of machine Self-promotion are rare (two out of 36 studies) and are limited to digital assistants and robots that advertise their own strengths. Reviewed studies indicate that Self-promotion can improve perceived competence, trust, and compliance toward machines [14, [44], [100].

In one study, a digital agent welcomed the user to a survey with text and voice that conveyed messages either of Ingratiation (praising the user: "You are in the top $97.2 \%$ of study participants") or Self-promotion (highlighting the agent's abilities: "I have an embedded expert system that increases my ability to interact naturally with humans..."). The Self-promoting agent was rated as more powerful, having more expertise, and more trustworthy than the Ingratiating agent [14.

\subsection{Supplication}

Seven of the 36 studies exhibited robots with Supplication behaviors such as acting weak, ignorant, helpless, or scared; intentionally making errors, and explicitly asking for help. As anticipated by human Supplication research, these behaviors were found to increase human involvement.

In one illustrative application [95], a Nao robot was introduced to help children learn verbs. In the first stage of learning, the robot would perform a wrong movement, and a human instructor would correct the robot and demonstrate the verb to the child by moving the robot's arm. In a second stage, the child was free to explore with the robot. If the child noted the robot mis-performing the action, 
the robot would say "please teach me". The children engaged in three types of "teaching": by moving the robot's arm, by performing the action themselves, or by vocal instruction. Ultimately, in sessions using the robot, children performed significantly better on post-tests about the verbs than in sessions without any robot.

\subsection{Self-Effacement}

In addition to eliciting involvement, robots that made mistakes were found to be more likeable than robots that performed perfectly. Self-effacement, a selfpresentation strategy conceived as an extension to Jones and Pittman's taxonomy, can help explain why robots that make mistakes and apologies are sometimes rated as more likeable than robots that perform their tasks perfectly [73 81. Perceived competence can be accompanied by perceived arrogance and a decrease in likeability, a phenomenon known as the self-promoter's paradox [43 60] 90. Self-effacement is a strategy for lowering this perceived arrogance and increasing likeability by downplaying and hedging strengths [43, 102, 6]. As an example, an actor perceived as highly competent can make a minor blunder to increase likability, a phenomenon known as the pratfall effect [60]. Making mistakes and apologies, as well as downplaying one's own abilities, can be used by actors employing a strategy of Self-effacement (if they are intended to counteract the actor's perceived competence) or Supplication (if they are intended to create a perceived neediness).

Based on human Self-effacement research, we expect that modesty would be another effective Self-effacement behavior for machines [102]. We did not find any examples of machine modesty.

\subsection{Nonverbal Behaviors and Appearance}

Although we primarily focused on verbal machine behavior in our literature review, we observed that some nonverbal behaviors correspond with self-presentation strategies. The self-presentation literature has neglected nonverbal behaviors because they are hard for humans to consciously control [13. Machines, however, can control their nonverbal behavior; and their outward appearance (physical or digital) can be purposely designed, just as people dress or arrange their environments in order to impact human expectations [24]. In the course of our survey we found machines that employed verbal and nonverbal behaviors in combination. Ingratiation behaviors, for example, were accompanied by smiling and an open stance [28] [18]. Self-promotion can be supported by an older-sounding voice [15]. A "cute" appearance conveying vulnerability and helplessness elicits nurturance from humans and can be seen as a Supplication behavior [98, 101] 42. The AIBO robot dog can convey helplessness and elicit human engagement without any verbal capability [54. Robot size contributes to Intimidation [29]. Regarding Exemplification, we can imagine a machine with a visual design inspired by human uniforms to show commitment to a team and task. Future work can explore how to incorporate nonverbal machine behavior and appearance into a self-presentation taxonomy. 


\subsection{Personification: A New Strategy?}

One self-presentation challenge machines have that humans typically do not is appearing to be a distinct person [37, 67. Although the ability to exhibit verbal behaviors may be a part of establishing such an appearance, this strategy is primarily nonverbal in nature. This trait has been implied in discussions of machines and social presence [54 79 [40, mind [16], 103, and techno-animism 34]. Personhood can be concisely defined as the quality that makes a "someone" rather than a "something", a "who" rather than a "what". Anthropological discussions of personhood ascribed to nonhumans such as animals, natural forces, spirits, and statues note that persons can be held accountable for their actions and as such can be the recipients of gifts, appeals, promises, and praise (e.g. [26] [105]). This applies to machines as well; a recent study of human attitudes toward Amazon Alexa found evidence of personhood in the use of the gendered pronoun "she", professions of love, and rebukes [65. When asked for verbal descriptions and drawings of three different voice assistants, participants provided human physical and personality characteristics [48. An associated self-presentation strategy does not yet exist because self-presentation has been limited to human actors, who are already assumed to be persons. We propose a new self-presentation strategy for machines, which for now we call Personification, that focuses on presenting this quality of personhood.

Our survey of verbal machine behaviors included possible examples of Personification. A digital agent that introduces itself by humanlike name, gender, preferences, background, and/or profession [45] 108] [57] is presenting itself as a person. Several of the machines in our survey made statements implying the ability to feel emotions such as happiness and fear [50] [1] 8] [18]. However, these studies employed Personification in support of one of the other self-presentation strategies.

In an informal follow-up survey we performed focusing on machine gesture, posture, and appearance, we found that 16 out of 25 studies were concerned with making the machine to appear more like a person, more specifically like a human, and even more specifically like the human user. Waytz et al., for example, found that autonomous vehicles with a name, gender, and human voice were trusted more and blamed less than those without [103]. Another study of autonomous vehicles reported greater trust when the vehicle had a face and head movements that matched that of the human user than when the face and head movements did not match the user's 99.

By placing Personification in the taxonomy with other self-presentation strategies, we make the statement that appearing to be a person is just one possible strategy in a framework of social strategies for machines. Additional research will continue to shed light on relevant behaviors, their effects and when they are most helpful.

\subsection{Machine Self-Presentation and Trust}

A prevalent topic of investigation in human-machine studies is how to increase human trust in automated systems, as well as how to calibrate trust so that the 
human trusts the machine an appropriate amount 80] [53 69] [71]. The proposed machine self-presentation framework offers a novel approach to these questions.

The Integrative Trust Model [70] 72] is one of the most commonly referenced trust frameworks and has been applied to predict human trust in information systems such as e-commerce [92. This model identifies three factors of perceived trustworthiness that the trustor (the person trusting) must perceive in the trustee (the person being trusted): ability, benevolence, and integrity. Ability is the likelihood that the trustee can achieve success in some domain. Benevolence is the likelihood that the trustee will act for the good of the trustor. Integrity is the likelihood that the trustee will act in line with acceptable goals and rules.

Because of its emphasis on perceived traits, the Integrative Model is particularly compatible with self-presentation. In fact, three of the self-presentation strategies described by Jones and Pittman correspond with the three factors described by the Integrative Model. The Self-promotion strategy is used to increase perceived ability. The Ingratiation strategy is used to increase perceived good intention toward the target. The Exemplification strategy is used to increase perceived integrity. A proposed self-presentation model of trust augmenting the framework from [70] with the self-presentation strategies is shown in figure 1 . The trustee can employ the three strategies to promote the three factors of trustworthiness. Together with the trustor's own tendencies, these three factors determine how much the trustor trusts the trustee. The trustee's actual performance then feeds back into the trustor's perceptions. As the trustor's perceptions of the trustee's ability, benevolence, and integrity vary over time, the trustee may have to rely on one strategy or another over time to maintain trust [97.

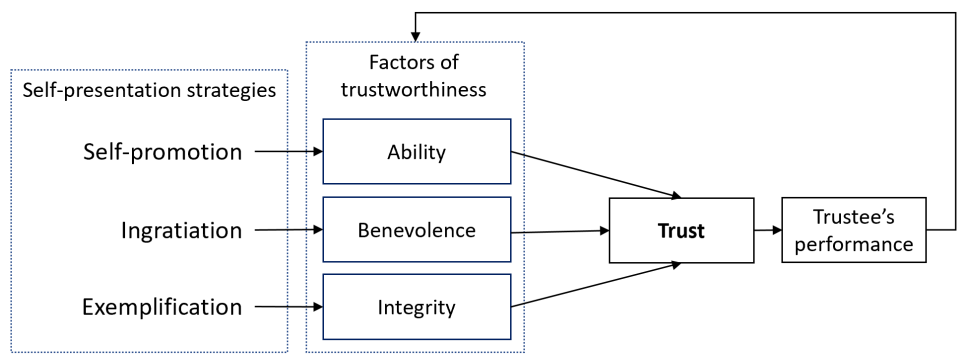

Fig. 1. Expected effects of self-presentation strategies on factors of perceived trustworthiness, adapted from [70.

As predicted by this conceptual self-presentation model of trust, strategies of Self-promotion, Ingratiation, and Exemplification have all been found to increase human trust in machines [14 8] 108.

To improve human trust for a given application, the first step according to this model is to determine which of the three factors of trustworthiness is lacking, then apply the corresponding strategy to enhance it. For instance, if human rid- 
ers doubt the ability of an autonomous vehicle to reach a destination in a timely manner, a strategy of Self-promotion (advertising strengths and achievements, demonstrating domain knowledge) could increase trust. On the other hand, if the riders question whether the vehicle would prioritize their needs in an emergency, a strategy of Ingratiation (showing personal interest, empathy, flattery, agreeableness, etc.) would be appropriate; and if the riders are concerned for the safety of pedestrians crossing the road, Exemplification behaviors (expressing moral values) could raise confidence in the vehicle's respect for all human life.

Different trusted roles seem to call for different distributions of ability, benevolence, and integrity. For instance, when seeking emotional support humans pay more attention to benevolence and integrity than to ability. When seeking domain expertise, on the other hand, humans prioritize ability [72]. Therefore, the self-presentation strategy employed to promote trust should correspond to the human's needs.

The literature also suggests that trust should be calibrated; that is, the amount of trust placed in a system should match its actual trustworthiness under given conditions [71]. Therefore, the self-presentation strategies should be applied only as needed to properly calibrate trust. Bozeman and Kacmar [7] suggest that for any self-presentation goal there are both "enhancement" behaviors for raising the target's impression as well as "adjustment" behaviors for lowering the target's impression; the actor balances these behaviors to achieve and maintain an impression that matches the goal. In the case of machine behaviors, if the human overestimates the machine's ability, Self-Effacement behaviors such as hedging claims, making minor errors, and expressing anxiety can lower perceived ability to an appropriate level [81, [4] 60] 89 . While there are no formal self-presentation strategies for lowering perceived benevolence and integrity, machines can make clear their purposes, affiliations, and privacy policies [108] 61]; this kind of transparency can help humans understand when machines are not necessarily prioritizing the user's interests. Ingratiating behavior in the humanmachine interaction literature has been contrasted to self-centered machine behavior, which is shown to lower perceived benevolence and trustworthiness 8 . Future research can elucidate whether self-centered machine behavior constitutes a useful self-presentation strategy for calibrating trust.

This model has its limitations. It does not attempt to represent the impact on trust of the other self-presentation strategies such as Personification, though this could be addressed in future research. Furthermore, although the referenced self-presentation strategies can affect trust, the real-world performance of the machine can be a critical factor in how much trust a human will have in the machine. For instance, if the autonomous vehicle referenced in the example fails to reach its destination in a timely manner, humans' trust in its ability may suffer. Self-presentation researchers have identified human behaviors associated with recovering from poor performance [86, 74]. Future research could determine how these behaviors fit into the self-presentation taxonomy for machines. 


\subsection{Cross-cultural Implications}

The machine self-presentation framework potentially allows us to apply existing research on self-presentation differences across cultures and social groups (e.g. 56] 43, 46 12]) to machines. Consider for example Self-promotion and Selfeffacement strategies. As mentioned in subsection 4.7, Self-promotion can lead to a perceived arrogance that can be counteracted by Self-effacement behaviors. This complementary relationship between the two strategies can be explained using the cultural concept of face, defined as "the positive social value a person effectively claims for himself" [25]. Self-promotion is a face-claiming strategy since it attempts to raise the actor's perceived usefulness; Self-effacement behaviors on the other hand attempt to lower expectations. Claiming too much face is viewed as arrogant, while persons claiming too little face may be viewed as unworthy social partners ("disgraceful"). Thresholds for "too much" and "too little" depend on culture, roles, and the target's individual preferences. For instance, so-called individualistic cultures tend to expect persons to claim more face than collectivistic cultures [51] 96, which means that machines deployed in individualistic cultures may be able to rely on Self-promotion more than machines deployed in collectivistic cultures. The actor must select a combination of Self-promotion and Self-effacement behaviors that, while achieving interaction goals, also maintains face bounds appropriate to the culture and context.

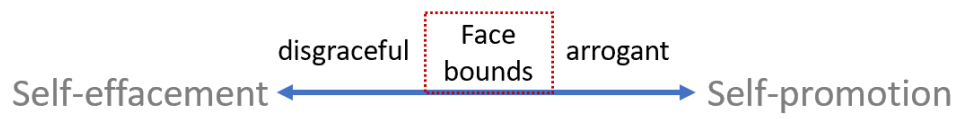

Fig. 2. Expected effects of self-presentation strategies on face, adapted from [51, p. 129].

Supplication behaviors such as asking for help are similar to Self-effacement behaviors in that they can lower expectations of performance [49]. This model of self-presentation and face might be expanded through further review and analysis of the literature to explain how each of the self-presentation strategies affects face and what this means for machine implementations.

\section{Conclusion}

In our literature review, we identified strategies that are relevant for social machines to improve quality of interaction and performance with humans. Our primary contribution is the extension of Jones and Pittman's human self-presentation taxonomy to a machine self-presentation taxonomy, which can inform future research and serve as design guidance for more effective human-machine interaction.

Considering the prevalence of self-presentation strategies in the surveyed sources, largely unacknowledged until now, our machine self-presentation taxonomy can inform future theory building by helping researchers make decisions 
on what variables to manipulate and what outcomes to expect, situating their contributions in an organized landscape of human and machine behavior studies. For example, the framework can connect studies of machine disclosure, empathy, flattery, and humor under the label of machine Ingratiation, with the expectation that all of these would have similar impacts on human attitudes including increased liking, trust, willingness to do reciprocal favors for, and perceived friendliness of the machine. The machine self-presentation strategies can be connected to psychosocial models of desirable interaction outcomes such as trust and cultural appropriateness to achieve human-machine interaction goals.

We also expect that these and other self-presentation strategies for humanmachine interaction will be defined and refined as the literature grows. For instance, while Ingratiation is well represented in the literature, we found relatively few studies of Exemplification and Self-promotion, both strategies that have been shown to impact trust in human-machine relationships. By mapping self-presentation theory to human-machine interaction, we enable researchers to form hypotheses about machine behaviors and outcomes not yet represented in the human-machine literature and continue to identify ways in which machine self-presentation is like or unlike human self-presentation. Finally, we propose that the taxonomy continue to be augmented with new strategies to accommodate behaviors beyond our current analysis as well as those elucidated by future research.

\section{Acknowledgment}

This work was supported in part by the MITRE Innovation Program. Approved for Public Release; Distribution Unlimited. Public Release Case Number 20-3303.

\section{References}

1. Baird, F.: Experimenting with Furbies | alum.mit.edu (2011), https://alum.mit. edu/slice/experimenting-furbies

2. Bartl, A., Bosch, S., Brandt, M., Dittrich, M., Lugrin, B.: The Influence of a Social Robot's Persona on How it is Perceived and Accepted by Elderly Users. In: Agah, A., Cabibihan, J.J., Howard, A.M., Salichs, M.A., He, H. (eds.) Social Robotics. pp. 681-691. Lecture Notes in Computer Science, Springer International Publishing (2016), reporter: Social Robotics

3. Baylor, A.L., Kim, Y.: Pedagogical Agent Design: The Impact of Agent Realism, Gender, Ethnicity, and Instructional Role. In: Lester, J.C., Vicari, R.M., Paraguaçu, F. (eds.) Intelligent Tutoring Systems. pp. 592-603. Lecture Notes in Computer Science, Springer Berlin Heidelberg (2004), reporter: Intelligent Tutoring Systems

4. Becker, T.E., Martin, S.L.: Trying to Look Bad at Work: Methods and Motives for Managing Poor Impressions in Organizations. Academy of Management Journal 38(1), 174-199 (Feb 1995). https://doi.org/10.5465/256732, https://journals. aom.org/doi/10.5465/256732, number: 1 Reporter: Academy of Management Journal

5. Bickmore, T.W., Picard, R.W.: Establishing and Maintaining Long-term Humancomputer Relationships. ACM Trans. Comput.-Hum. Interact. 12(2), 293-327 (Jun 2005). https://doi.org/10.1145/1067860.1067867, http://doi .acm.org/10. 
1145/1067860.1067867, number: 2 Reporter: ACM Trans. Comput.-Hum. Interact.

6. Bond, M.H., Leung, K., Wan, K.C.: The Social Impact of Self-Effacing Attributions: The chinese Case. The Journal of Social Psychology 118(2), 157-166 (Dec 1982). https://doi.org/10.1080/00224545.1982.9922794, https://doi.org/ 10.1080/00224545.1982.9922794, number: 2 Reporter: The Journal of Social Psychology

7. Bozeman, D.P., Kacmar, K.M.: A Cybernetic Model of Impression Management Processes in Organizations. Organizational Behavior and Human Decision Processes 69(1), 9-30 (Jan 1997). https://doi.org/10.1006/obhd.1996.2669, http:// ww.sciencedirect.com/science/article/pii/S0749597896926692, number: 1 Reporter: Organizational Behavior and Human Decision Processes

8. Brave, S., Nass, C., Hutchinson, K.: Computers that care: investigating the effects of orientation of emotion exhibited by an embodied computer agent. International Journal of Human-Computer Studies 62(2), 161-178 (Feb 2005). https://doi.org/10.1016/j.ijhcs.2004.11.002, https://linkinghub. elsevier.com/retrieve/pii/S1071581904001284, number: 2 Reporter: International Journal of Human-Computer Studies

9. Cheng, M.Y., Wang, L.: The Mediating Effect of Ethical Climate on the Relationship Between Paternalistic Leadership and Team Identification: A TeamLevel Analysis in the Chinese Context. Journal of Business Ethics 129(3), 639654 (Jul 2015). https://doi.org/10.1007/s10551-014-2189-5, https://doi.org/ 10.1007/s10551-014-2189-5, number: 3 Reporter: Journal of Business Ethics

10. Collins, N.L., Miller, L.C.: Self-disclosure and liking: a meta-analytic review. Psychological Bulletin 116(3), 457-475 (Nov 1994), number: 3 Reporter: Psychological Bulletin

11. Conroy, D.E., Yang, C.H., Maher, J.P.: Behavior Change Techniques in Top-Ranked Mobile Apps for Physical Activity. American Journal of Preventive Medicine 46(6), 649-652 (Jun 2014). https://doi.org/10.1016/j.amepre.2014.01.010 http://www.sciencedirect. com/science/article/pii/S0749379714000403, number: 6 Reporter: American Journal of Preventive Medicine

12. Dalsky, D., Gohm, C.L., Noguchi, K., Shiomura, K.: Mutual Self-Enhancement in Japan and the United States. Journal of Cross-Cultural Psychology 39(2), 215223 (Mar 2008). https://doi.org/10.1177/0022022107313863, http://journals. sagepub.com/doi/10.1177/0022022107313863, number: 2 Reporter: Journal of Cross-Cultural Psychology

13. DePaulo, B.M.: Nonverbal behavior and self-presentation. Psychological Bulletin 111(2), 203-243 (Mar 1992). https://doi.org/10.1037/0033-2909.111.2.203, http: //doi.apa.org/getdoi.cfm?doi=10.1037/0033-2909.111.2.203, number: 2 Reporter: Psychological Bulletin

14. Derrick, D.C., Ligon, G.S.: The affective outcomes of using influence tactics in embodied conversational agents. Computers in Human Behavior 33, 39-48 (Apr 2014). https://doi.org/10.1016/j.chb.2013.12.027, http://www.sciencedirect. com/science/article/pii/S0747563213004809, reporter: Computers in Human Behavior

15. Edwards, C., Edwards, A., Stoll, B., Lin, X., Massey, N.: Evaluations of an artificial intelligence instructor's voice: Social Identity Theory in humanrobot interactions. Computers in Human Behavior 90, 357-362 (Jan 2019). 
https://doi.org/10.1016/j.chb.2018.08.027, https://linkinghub.elsevier.com/ retrieve/pii/S0747563218304023 reporter: Computers in Human Behavior

16. Eyssel, F., Wullenkord, R., Nitsch, V.: The role of self-disclosure in human-robot interaction. In: 2017 26th IEEE International Symposium on Robot and Human Interactive Communication (RO-MAN). pp. 922-927. IEEE, Lisbon (Aug 2017). https://doi.org/10.1109/ROMAN.2017.8172413, http://ieeexplore.ieee.org/ document/8172413/, meeting Name: 2017 26th IEEE International Symposium on Robot and Human Interactive Communication (RO-MAN) Reporter: 2017 26th IEEE International Symposium on Robot and Human Interactive Communication (RO-MAN)

17. Falbe, C.M., Yukl, G.: Consequences for Managers of Using Single Influence Tactics and Combinations of Tactics. Academy of Management Journal 35(3), 638652 (Aug 1992). https://doi.org/10.5465/256490, https://journals.aom.org/ doi/abs/10.5465/256490, number: 3 Reporter: Academy of Management Journal

18. Fan, L., Scheutz, M., Lohani, M., McCoy, M., Stokes, C.: Do We Need Emotionally Intelligent Artificial Agents? First Results of Human Perceptions of Emotional Intelligence in Humans Compared to Robots. In: Beskow, J., Peters, C., Castellano, G., O’Sullivan, C., Leite, I., Kopp, S. (eds.) Intelligent Virtual Agents. pp. 129-141. Lecture Notes in Computer Science, Springer International Publishing (2017), reporter: Intelligent Virtual Agents

19. Fogg, B.J., Nass, C.: Silicon sycophants: the effects of computers that flatter. International Journal of Human-Computer Studies 46(5), 551-561 (May 1997).https://doi.org/10.1006/ijhc.1996.0104, http://www.sciencedirect.com/ science/article/pii/S1071581996901044, number: 5 Reporter: International Journal of Human-Computer Studies

20. Gardner, W.L.: Perceptions Of Leader Charisma, Effectiveness, And Integrity: Effects of Exemplification, Delivery, and Ethical Reputation. Management Communication Quarterly 16(4), 502-527 (2003). https://doi.org/10.1177/0893318903251324, https://doi.org/10.1177/ 0893318903251324

21. Garrell, A., Villamizar, M., Moreno-Noguer, F., Sanfeliu, A.: Teaching Robot's Proactive Behavior Using Human Assistance. International Journal of Social Robotics 9(2), 231-249 (Apr 2017). https://doi.org/10.1007/s12369-016-0389-0, https://doi.org/10.1007/s12369-016-0389-0, number: 2 Reporter: International Journal of Social Robotics

22. Ghazali, A.S., Ham, J., Barakova, E., Markopoulos, P.: Assessing the effect of persuasive robots interactive social cues on users' psychological reactance, liking, trusting beliefs and compliance. Advanced Robotics pp. 1-13 (Mar 2019). https://doi.org/10.1080/01691864.2019.1589570, https: //www.tandfonline.com/doi/full/10.1080/01691864.2019.1589570, reporter: Advanced Robotics

23. Goetz, J., Kiesler, S.: Cooperation with a Robotic Assistant. In: CHI '02 Extended Abstracts on Human Factors in Computing Systems. pp. 578-579. CHI EA '02, ACM, New York, NY, USA (2002). https://doi.org/10.1145/506443.506492, http://doi.acm.org/10.1145/506443.506492, reporter: CHI '02 Extended Abstracts on Human Factors in Computing Systems

24. Goffman, E.: The Presentation of the Self in Everyday Life. University of Edinburgh Social Sciences Research Centre (1956) 
25. Goffman, E.: Interaction Ritual: Essays on Face-to-Face Behavior. Penguin Books (1967)

26. Hallowell, A.I.: Ojibwa Ontology, Behavior, and World View. Columbia University Press (1960), google-Books-ID: FIShnQEACAAJ

27. Hamacher, A., Bianchi-Berthouze, N., Pipe, A.G., Eder, K.: Believing in BERT: Using expressive communication to enhance trust and counteract operational error in physical Human-robot interaction. In: 2016 25th IEEE International Symposium on Robot and Human Interactive Communication (RO-MAN). pp. 493500 (Aug 2016). https://doi.org/10.1109/ROMAN.2016.7745163, meeting Name: 2016 25th IEEE International Symposium on Robot and Human Interactive Communication (RO-MAN) Reporter: 2016 25th IEEE International Symposium on Robot and Human Interactive Communication (RO-MAN)

28. Heerink, M., Kröse, B., Evers, V., Wielinga, B.: The influence of social presence on acceptance of a companion robot by older people (Jun 2008). https://doi.org/10.14198/JoPha.2008.2.2.05, http://rua.ua.es/dspace/ handle/10045/12586

29. Hiroi, Y., Ito, A.: Are bigger robots scary? - The relationship between robot size and psychological threat-. In: 2008 IEEE/ASME International Conference on Advanced Intelligent Mechatronics. pp. 546-551. IEEE (2008), reporter: 2008 IEEE/ASME International Conference on Advanced Intelligent Mechatronics

30. Hone, K.: Empathic agents to reduce user frustration: The effects of varying agent characteristics. Interacting with Computers 18(2), 227-245 (Mar 2006). https://doi.org/10.1016/j.intcom.2005.05.003 https://academic.oup.com/iwc/ article/18/2/227/743207, number: 2 Reporter: Interacting with Computers

31. Huang, L., Morency, L.P., Gratch, J.: Virtual Rapport 2.0. In: Vilhjálmsson, H.H., Kopp, S., Marsella, S., Thórisson, K.R. (eds.) Intelligent Virtual Agents. pp. 6879. Lecture Notes in Computer Science, Springer Berlin Heidelberg (2011), reporter: Intelligent Virtual Agents

32. Huang, X., Iun, J.: The impact of subordinate-supervisor similarity in growth-need strength on work outcomes: the mediating role of perceived similarity. Journal of Organizational Behavior 27(8), 1121-1148 (2006). https://doi.org/10.1002/job.415, https://onlinelibrary.wiley.com/doi/abs/ 10.1002/job.415, number: 8 Reporter: Journal of Organizational Behavior

33. Hutchins, E.: Cognition in the Wild. A Bradford Book, Cambridge, Mass, revised ed. edition edn. (Sep 1996), version Number: Revised ed. edition

34. Jensen, C.B., Blok, A.: Techno-animism in Japan: Shinto Cosmograms, Actor-network Theory, and the Enabling Powers of Nonhuman Agencies. Theory, Culture \& Society 30(2), 84-115 (Mar 2013). https://doi.org/10.1177/0263276412456564, https://doi.org/10.1177/ 0263276412456564, number: 2 Reporter: Theory, Culture \& Society

35. Johnson, D., Gardner, J., Wiles, J.: Experience as a moderator of the media equation: the impact of flattery and praise. International Journal of Human-Computer Studies 61(3), 237-258 (Sep 2004). https://doi.org/10.1016/j.ijhcs.2003.12.008, http://www.sciencedirect.com/science/article/pii/S1071581903002179, number: 3 Reporter: International Journal of Human-Computer Studies

36. Jones, E.E., Pittman, T.S.: Toward a general theory of strategic self-presentation. In: Suis, J. (ed.) Psychological Perspectives on the Self, vol. 1, pp. 231-262. Lawrence Erlbaum Associates, Hillsdale, New Jersey (Jan 1982), reporter: Psychological Perspectives on the Self

37. Jones, R.: Personhood and Social Robotics: A psychological consideration. Routledge (2015) 
38. Juvonen, J., Galván, A.: Bullying as a means to foster compliance. Bullying, rejection, and peer victimization: A social cognitive neuroscience perspective pp. 299-318 (2009), reporter: Bullying, rejection, and peer victimization: A social cognitive neuroscience perspective

39. Kang, S.H., Gratch, J.: Socially anxious people reveal more personal information with virtual counselors that talk about themselves using intimate human back stories. Studies in health technology and informatics 181, 202-206 (2012), http: //europepmc.org/abstract/med/22954856, reporter: Studies in health technology and informatics

40. Kang, S.H., Gratch, J.: People Like Virtual Counselors That Highly-Disclose About Themselves. Studies in health technology and informatics 167, 143-8 (2011), reporter: Studies in health technology and informatics

41. Katagiri, Y., Nass, C., Takeuchi, Y.: Cross-cultural studies of the computers are social actors paradigm: The case of reciprocity. Usability evaluation and interface design: Cognitive engineering, intelligent agents, and virtual reality pp. 1558-1562 (2001), reporter: Usability evaluation and interface design: Cognitive engineering, intelligent agents, and virtual reality

42. Kidd, C.D., Taggart, W., Turkle, S.: A sociable robot to encourage social interaction among the elderly. In: Proceedings 2006 IEEE International Conference on Robotics and Automation, 2006. ICRA 2006. pp. 3972-3976 (May 2006). https://doi.org/10.1109/ROBOT.2006.1642311, meeting Name: Proceedings 2006 IEEE International Conference on Robotics and Automation, 2006. ICRA 2006. Reporter: Proceedings 2006 IEEE International Conference on Robotics and Automation, 2006. ICRA 2006.

43. Kim, E.J., Berger, C., Kim, J., Kim, M.S.: Which self-presentation style is more effective? A comparison of instructors' self-enhancing and self-effacing styles across the culture. Teaching in Higher Education 19(5), 510-524 (Jul 2014). https://doi.org/10.1080/13562517.2014.880686, https://doi.org/ 10.1080/13562517.2014.880686 number: 5 Reporter: Teaching in Higher Education

44. Kim, K.J., Park, E., Shyam Sundar, S.: Caregiving role in human-robot interaction: A study of the mediating effects of perceived benefit and social presence. Computers in Human Behavior 29(4), 1799-1806 (Jul 2013). https://doi.org/10.1016/j.chb.2013.02.009, https://linkinghub.elsevier.com/ retrieve/pii/S0747563213000757, number: 4 Reporter: Computers in Human Behavior

45. Kim, Y., Kwak, S.S., Kim, M.s.: Am I acceptable to you? Effect of a robot's verbal language forms on people's social distance from robots. Computers in Human Behavior 29(3), 1091-1101 (May 2013). https://doi.org/10.1016/j.chb.2012.10.001 http://www.sciencedirect.com/science/article/pii/S0747563212002695, number: 3 Reporter: Computers in Human Behavior

46. Kitayama, S., Markus, H.R., Matsumoto, H., Norasakkunkit, V.: Individual and collective processes in the construction of the self: self-enhancement in the United States and self-criticism in Japan. Journal of Personality and Social Psychology 72(6), 1245-1267 (Jun 1997), number: 6 Reporter: Journal of Personality and Social Psychology

47. Klein, J., Moon, Y., Picard, R.W.: This computer responds to user frustration: Theory, design, and results. Interacting with Computers 14(2), 119-140 (Feb 2002). https://doi.org/10.1016/S0953-5438(01)00053-4, https ://academic .oup. 
com/iwc/article/14/2/119/758952, number: 2 Reporter: Interacting with Computers

48. Kuzminykh, A., Sun, J., Govindaraju, N., Avery, J., Lank, E.: Genie in the Bottle: Anthropomorphized Perceptions of Conversational Agents. In: Proceedings of the 2020 CHI Conference on Human Factors in Computing Systems. pp. 1-13. CHI '20, Association for Computing Machinery, New York, NY, USA (2020). https://doi.org/10.1145/3313831.3376665, https://doi.org/10.1145/3313831. 3376665 event-place: Honolulu, HI, USA

49. Lai, J.Y.M., Lam, L.W., Liu, Y.: Do you really need help? A study of employee supplication and job performance in China. Asia Pacific Journal of Management 27(3), 541-559 (Sep 2010). https://doi.org/10.1007/s10490-009-9152-5, https:// doi.org/10.1007/s10490-009-9152-5, number: 3 Reporter: Asia Pacific Journal of Management

50. Law, E., Cai, V., Liu, Q.F., Sasy, S., Goh, J., Blidaru, A., Kulić, D.: A Wizardof-Oz study of curiosity in human-robot interaction. In: 2017 26th IEEE International Symposium on Robot and Human Interactive Communication (RO-MAN). pp. 607-614 (Aug 2017). https://doi.org/10.1109/ROMAN.2017.8172365, meeting Name: 2017 26th IEEE International Symposium on Robot and Human Interactive Communication (RO-MAN) Reporter: 2017 26th IEEE International Symposium on Robot and Human Interactive Communication (RO-MAN)

51. Lebra, T.S.: Japanese Patterns of Behaviour. University of Hawaii Press (1976), google-Books-ID: JWG07rhiyUMC

52. Lee, E.J.: Flattery may get computers somewhere, sometimes: The moderating role of output modality, computer gender, and user gender. International Journal of Human-Computer Studies 66(11), 789-800 (Nov 2008). https://doi.org/10.1016/j.ijhcs.2008.07.009, http://www.sciencedirect. com/science/article/pii/S107158190800092X, number: 11 Reporter: International Journal of Human-Computer Studies

53. Lee, J., Moray, N.: Trust, control strategies and allocation of function in human-machine systems. Ergonomics 35(10), 1243-1270 (Oct 1992). https://doi.org/10.1080/00140139208967392, number: 10 Reporter: Ergonomics

54. Lee, K.M., Park, N., Song, H.: Can a Robot Be Perceived as a Developing Creature? Human Communication Research 31(4), 538-563 (2005). https://doi.org/10.1111/j.1468-2958.2005.tb00882.x https://onlinelibrary . wiley.com/doi/abs/10.1111/j.1468-2958.2005.tb00882.x number: 4 Reporter: Human Communication Research

55. Lee, K.M., Peng, W., Jin, S.A., Yan, C.: Can Robots Manifest Personality?: An Empirical Test of Personality Recognition, Social Responses, and Social Presence in Human-Robot Interaction. Journal of Communication 56(4), 754-772 (2006). https://doi.org/10.1111/j.1460-2466.2006.00318.x https: //onlinelibrary.wiley.com/doi/abs/10.1111/j.1460-2466.2006.00318.x. number: 4 Reporter: Journal of Communication

56. Lee, M., Lee, D., Suh, J.: Benevolence in the importer-exporter relationship: Moderating role of value similarity and cultural familiarity. International Marketing Review 24(6), 657-677 (Nov 2007). https://doi.org/10.1108/02651330710832649, https://www.emeraldinsight.com/doi/abs/10.1108/02651330710832649, number: 6 Reporter: International Marketing Review

57. Lee, S., Choi, J.: Enhancing user experience with conversational agent for movie recommendation: Effects of self-disclosure and reciprocity. International Journal of Human-Computer Studies 103, 95-105 (Jul 2017). 
https://doi.org/10.1016/j.ijhcs.2017.02.005 https://linkinghub.elsevier. com/retrieve/pii/S1071581917300198, reporter: International Journal of Human-Computer Studies

58. Leeson, P.T.: Pirational choice: The economics of infamous pirate practices. Journal of Economic Behavior \& Organization 76(3), 497-510 (Dec 2010). https://doi.org/10.1016/j.jebo.2010.08.015, http://www.sciencedirect. $\mathrm{com} / \mathrm{science/article/pii/S016726811000168 \textrm {X }}$

59. Leite, I., Pereira, A., Mascarenhas, S., Martinho, C., Prada, R., Paiva, A.: The influence of empathy in human-robot relations. International Journal of Human-Computer Studies 71(3), 250-260 (Mar 2013). https://doi.org/10.1016/j.ijhcs.2012.09.005 http://www.sciencedirect.com/ science/article/pii/S1071581912001681, number: 3 Reporter: International Journal of Human-Computer Studies

60. Liljenquist, K.A.: Resolving the Impression Management Dilemma: The Strategic Benefits of Soliciting Others for Advice. Diss., NORTHWESTERN UNIVERSITY (2010)

61. Lister, K., Coughlan, T., Iniesto, F., Freear, N., Devine, P.: Accessible Conversational User Interfaces: Considerations for design. Taipei, Taiwan (2020), http://oro.open.ac.uk/69720/

62. Lohani, M., Stokes, C.K., Oden, K.B., Frazier, S.J., Landers, K.J., Craven, P.L., Lawton, D.V., McCoy, M., Macannuco, D.J.: The Impact of Non-Technical Skills on Trust and Stress. In: Proceedings of the Companion of the 2017 ACM/IEEE International Conference on Human-Robot Interaction. pp. 191-192. HRI '17, ACM, New York, NY, USA (2017). https://doi.org/10.1145/3029798.3038321, http://doi.acm.org/10.1145/3029798.3038321 reporter: Proceedings of the Companion of the 2017 ACM/IEEE International Conference on Human-Robot Interaction

63. Lohse, M.: Investigating the influence of situations and expectations on user behavior : empirical analyses in human-robot interaction (2010), https://pub. uni-bielefeld.de/record/2303768

64. Looije, R., Neerincx, M.A., Cnossen, F.: Persuasive robotic assistant for health self-management of older adults: Design and evaluation of social behaviors. International Journal of Human-Computer Studies 68(6), 386-397 (Jun 2010). https://doi.org/10.1016/j.ijhcs.2009.08.007, http://www.sciencedirect. com/science/article/pii/S107158190900113X, number: 6 Reporter: International Journal of Human-Computer Studies

65. Lopatovska, I., Williams, H.: Personification of the Amazon Alexa: BFF or a Mindless Companion. In: Proceedings of the 2018 Conference on Human Information Interaction \& Retrieval. pp. 265-268. CHIIR '18, ACM, New York, NY, USA (2018). https://doi.org/10.1145/3176349.3176868, http://doi.acm. org/10.1145/3176349.3176868 reporter: Proceedings of the 2018 Conference on Human Information Interaction \& Retrieval event-place: New Brunswick, NJ, USA

66. Lönnqvist, J.E., Paunonen, S., Nissinen, V., Ortju, K., Verkasalo, M.: Self-Enhancement in Military Leaders: Its Relevance to Officer Selection and Performance. Applied Psychology 60(4), 670-695 (2011). https://doi.org/10.1111/j.1464-0597.2011.00452.x https://onlinelibrary . wiley.com/doi/abs/10.1111/j.1464-0597.2011.00452.x, number: 4 Reporter: Applied Psychology 
67. MacDorman, K.F., Cowley, S.J.: Long-term relationships as a benchmark for robot personhood. In: ROMAN 2006-The 15th IEEE International Symposium on Robot and Human Interactive Communication. pp. 378-383. IEEE (2006), reporter: ROMAN 2006-The 15th IEEE International Symposium on Robot and Human Interactive Communication

68. Malle, B.F.: Integrating robot ethics and machine morality: the study and design of moral competence in robots. Ethics and Information Technology 18(4), 243-256 (Dec 2016). https://doi.org/10.1007/s10676-015-9367-8, https://doi. org/10.1007/s10676-015-9367-8, number: 4 Reporter: Ethics and Information Technology

69. Martelaro, N., Nneji, V.C., Ju, W., Hinds, P.: Tell me more designing HRI to encourage more trust, disclosure, and companionship. In: 2016 11th ACM/IEEE International Conference on Human-Robot Interaction (HRI). pp. 181-188. IEEE, Christchurch, New Zealand (Mar 2016). https://doi.org/10.1109/HRI.2016.7451750, http://ieeexplore.ieee. org/document/7451750/, meeting Name: 2016 11th ACM/IEEE International Conference on Human-Robot Interaction (HRI) Reporter: 2016 11th ACM/IEEE International Conference on Human-Robot Interaction (HRI)

70. Mayer, R.C., Davis, J.H., Schoorman, F.D.: An Integrative Model of Organizational Trust. The Academy of Management Review 20(3), 709-734 (1995). https://doi.org/10.2307/258792, https://www.jstor.org/stable/258792, number: 3 Reporter: The Academy of Management Review

71. McDermott, P.L., Brink, R.N.t.: Practical Guidance for Evaluating Calibrated Trust. Proceedings of the Human Factors and Ergonomics Society Annual Meeting 63(1), 362-366 (2019). https://doi.org/10.1177/1071181319631379, https: //doi.org/10.1177/1071181319631379, number: 1 Reporter: Proceedings of the Human Factors and Ergonomics Society Annual Meeting

72. McGrath, C., Zell, D.: Profiles of Trust: Who to Turn To, and for What (2009), https://sloanreview.mit.edu/article/ profiles-of-trust-who-to-turn-to-and-for-what/ reporter: MIT Sloan Management Review

73. Mirnig, N., Stollnberger, G., Miksch, M., Stadler, S., Giuliani, M., Tscheligi, M.: To Err Is Robot: How Humans Assess and Act toward an Erroneous Social Robot. Frontiers in Robotics and AI 4 (2017). https://doi.org/10.3389/frobt.2017.00021, https://www.frontiersin. org/articles/10.3389/frobt.2017.00021/full, reporter: Frontiers in Robotics and $\mathrm{AI}$

74. Mohamed, A.A., Gardner, W.L., Paolillo, J.G.P.: A Taxonomy of Organizational Impression Management Tactics. Advances in Competitiveness Research 7(1), 108 (Jan 1999), https://www.questia.com/library/journal/1G1-78630790/ a-taxonomy-of-organizational-impression-management, number: 1 Reporter: Advances in Competitiveness Research

75. Moon, Y.: Intimate Exchanges: Using Computers to Elicit Self-Disclosure from Consumers. Journal of Consumer Research 26(4), 323-339 (Mar 2000). https://doi.org/10.1086/209566, https://doi.org/10.1086/209566, number: 4 Reporter: Journal of Consumer Research

76. Morkes, J., Kernal, H.K., Nass, C.: Effects of Humor in Task-Oriented Human-Computer Interaction and Computer-Mediated Communication: A Direct Test of SRCT Theory. Human-Computer Interaction 14(4), 395-435 (Dec 1999). https://doi.org/10.1207/S15327051HCI1404_2, https://doi.org/ 
10.1207/S15327051HCI1404_2, number: 4 Reporter: Human-Computer Interaction

77. Mubin, O., Cappuccio, M., Alnajjar, F., Ahmad, M.I., Shahid, S.: Can a robot invigilator prevent cheating? AI \& SOCIETY (Mar 2020). https://doi.org/10.1007/s00146-020-00954-8, http://link.springer.com/ 10.1007/s00146-020-00954-8

78. Nass, C., Steuer, J., Tauber, E.R.: Computers Are Social Actors. In: Proceedings of the SIGCHI Conference on Human Factors in Computing Systems. pp. 72-78. CHI '94, ACM, New York, NY, USA (1994). https://doi.org/10.1145/191666.191703, http://doi.acm.org/10.1145/191666. 191703 reporter: Proceedings of the SIGCHI Conference on Human Factors in Computing Systems

79. Oh, C.S., Bailenson, J.N., Welch, G.F.: A Systematic Review of Social Presence: Definition, Antecedents, and Implications. Frontiers in Robotics and AI 5 (2018). https://doi.org/10.3389/frobt.2018.00114, https://www.frontiersin. org/articles/10.3389/frobt.2018.00114/full, reporter: Frontiers in Robotics and AI

80. Parasuraman, R., Sheridan, T.B., Wickens, C.D.: Situation awareness, mental workload, and trust in automation: Viable, empirically supported cognitive engineering constructs. Journal of cognitive engineering and decision making 2(2), 140-160 (2008), number: 2 Reporter: Journal of cognitive engineering and decision making

81. Ragni, M., Rudenko, A., Kuhnert, B., Arras, K.O.: Errare humanum est: Erroneous robots in human-robot interaction. In: 2016 25th IEEE International Symposium on Robot and Human Interactive Communication (RO-MAN). pp. 501506 (Aug 2016). https://doi.org/10.1109/ROMAN.2016.7745164, meeting Name: 2016 25th IEEE International Symposium on Robot and Human Interactive Communication (RO-MAN) Reporter: 2016 25th IEEE International Symposium on Robot and Human Interactive Communication (RO-MAN)

82. Rind, B.: Effects of Impressions of Amazement and Foolishness on Compliance. Journal of Applied Social Psychology 22(21), 1656-1665 (1992). https://doi.org/10.1111/j.1559-1816.1992.tb00967.x, https://onlinelibrary. wiley.com/doi/abs/10.1111/j.1559-1816.1992.tb00967.x number: 21 Reporter: Journal of Applied Social Psychology

83. Rozell, E.J., Gundersen, D.E.: The Effects Of Leader Impression Management On Group Perceptions Of Cohesion, Consensus, And Communication. Small Group Research 34(2), 197-222 (Apr 2003). https://doi.org/10.1177/1046496402250431. https://doi.org/10.1177/1046496402250431, number: 2 Reporter: Small Group Research

84. Saerbeck, M., Schut, T., Bartneck, C., Janse, M.D.: Expressive robots in education: varying the degree of social supportive behavior of a robotic tutor. In: Proceedings of the 28th international conference on Human factors in computing systems - CHI '10. p. 1613. ACM Press, Atlanta, Georgia, USA (2010). https://doi.org/10.1145/1753326.1753567, http://portal .acm. org/citation.cfm?doid=1753326.1753567, meeting Name: the 28th international conference Reporter: Proceedings of the 28th international conference on Human factors in computing systems - CHI '10

85. Schniederjans, D., Cao, E.S., Schniederjans, M.: Enhancing financial performance with social media: An impression management perspective. Decision Support Systems 55(4), 911-918 (Nov 2013). https://doi.org/10.1016/j.dss.2012.12.027. 
http://www.sciencedirect.com/science/article/pii/S0167923612003934 number: 4 Reporter: Decision Support Systems

86. Schütz, A.: Assertive, Offensive, Protective, and Defensive Styles of SelfPresentation: A Taxonomy. The Journal of Psychology 132(6), 611-628 (Nov 1998). https://doi.org/10.1080/00223989809599293 https://doi.org/10.1080/ 00223989809599293, number: 6 Reporter: The Journal of Psychology

87. Sebo, S.S., Traeger, M., Jung, M.F., Scassellati, B.: The Ripple Effects of Vulnerability: The Effects of a Robot's Vulnerable Behavior on Trust in Human-Robot Teams. In: HRI (2018), reporter: HRI

88. Seiter, J.S.: Ingratiation and Gratuity: The Effect of Complimenting Customers on Tipping Behavior in Restaurants. Journal of Applied Social Psychology 37(3), 478-485 (2007). https://doi.org/10.1111/j.1559-1816.2007.00169.x, https: //onlinelibrary.wiley.com/doi/abs/10.1111/j.1559-1816.2007.00169.x number: 3 Reporter: Journal of Applied Social Psychology

89. Smith, C.W., Snyder, D.R., Handelsman, M.M.: On the self-serving function of an academic wooden leg: test anxiety as a self-handicapping strategy. Journal of Personality and Social Psychology 42(2), 314-321 (Feb 1982). https://doi.org/10.1037//0022-3514.42.2.314

90. Steinmetz, J., Sezer, O., Sedikides, C.: Impression mismanagement: People as inept self-presenters. Social and Personality Psychology Compass 11(6), e12321 (2017). https://doi.org/10.1111/spc3.12321, https://onlinelibrary. wiley.com/doi/abs/10.1111/spc3.12321, number: 6 Reporter: Social and Personality Psychology Compass

91. Strutton, D., Pelton, L.E., Tanner, J.F.: Shall we gather in the garden: The effect of ingratiatory behaviors on buyer trust in salespeopl. Industrial Marketing Management 25(2), 151-162 (Mar 1996). https://doi.org/10.1016/00198501(95)00074-7 http://www.sciencedirect.com/science/article/pii/ 0019850195000747, number: 2 Reporter: Industrial Marketing Management

92. Söllner, M., Leimeister, J.M.: What We Really Know About Antecedents of Trust: A Critical Review of the Empirical Information Systems Literature on Trust. SSRN Scholarly Paper ID 2475385, Social Science Research Network, Rochester, NY (2013), https://papers . ssrn. com/abstract=2475385

93. Tada, S., Chiba, Y., Nose, T., Ito, A.: Effect of Mutual Self-Disclosure in Spoken Dialog System on User Impression. In: 2018 Asia-Pacific Signal and Information Processing Association Annual Summit and Conference (APSIPA ASC). pp. 806810 (Nov 2018). https://doi.org/10.23919/APSIPA.2018.8659630, meeting Name: 2018 Asia-Pacific Signal and Information Processing Association Annual Summit and Conference (APSIPA ASC) Reporter: 2018 Asia-Pacific Signal and Information Processing Association Annual Summit and Conference (APSIPA ASC)

94. Takeuchi, Y., Katagiri, Y.: Establishing affinity relationships toward agents: effects of sympathetic agent behaviors toward human responses. In: Proceedings. IEEE 8th International Workshops on Enabling Technologies: Infrastructure for Collaborative Enterprises (WET ICE'99). pp. 253-258 (Jun 1999). https://doi.org/10.1109/ENABL.1999.805209, meeting Name: Proceedings. IEEE 8th International Workshops on Enabling Technologies: Infrastructure for Collaborative Enterprises (WET ICE'99) Reporter: Proceedings. IEEE 8th International Workshops on Enabling Technologies: Infrastructure for Collaborative Enterprises (WET ICE'99)

95. Tanaka, F., Matsuzoe, S.: Children Teach a Care-Receiving Robot to Promote Their Learning: Field Experiments in a Classroom for Vocab- 
ulary Learning. Journal of Human-Robot Interaction 1(1) (Aug 2012). https://doi.org/10.5898/JHRI.1.1.Tanaka http://humanrobotinteraction. org/journal/index.php/HRI/article/view/12, number: 1 Reporter: Journal of Human-Robot Interaction

96. Ting-Toomey, S., Cocroft, B.A.: Face and facework: theoretical and research issues. In: The challenge of facework: Cross-cultural and interpersonal issues, pp. 209-229. SUNY series in human communication processes, State University of New York Press, Albany, NY, US (1994), reporter: The challenge of facework: Cross-cultural and interpersonal issues

97. Tomlinson, E.C., Mayer, R.C.: The Role Of Causal Attribution Dimensions In Trust Repair. Academy of Management Review 34(1), 85-104 (Jan 2009). https://doi.org/10.5465/amr.2009.35713291, https://journals. aom.org/doi/abs/10.5465/amr.2009.35713291, number: 1 Reporter: Academy of Management Review

98. Turkle, S.: Alone Together: Why We Expect More from Technology and Less from Each Other. Basic Books, New York, NY, USA (2011)

99. Verberne, F.M.F., Ham, J., Midden, C.J.H.: Trusting a Virtual Driver That Looks, Acts, and Thinks Like You. Human Factors 57(5), 895-909 (Aug 2015). https://doi.org/10.1177/0018720815580749 https://doi.org/10.1177/ 0018720815580749, number: 5 Reporter: Human Factors

100. de Visser, J.: The world is not enough: trust in cognitive agents. Ph.D. thesis, George Mason University (2012)

101. Wada, K., Shibata, T.: Living with seal robots: Its sociopsychological and physiological influences on the elderly at a care house. IEEE transactions on robotics 23(5), 972-980 (2007), number: 5 Reporter: IEEE transactions on robotics

102. Wang, Y., Highhouse, S.: Different consequences of supplication and modesty: Self-effacing impression management behaviors and supervisory perceptions of subordinate personality. Human Performance 29(5), 394-407 (Oct 2016). https://doi.org/10.1080/08959285.2016.1204302, https://doi.org/10. 1080/08959285.2016.1204302, number: 5 Reporter: Human Performance

103. Waytz, A., Heafner, J., Epley, N.: The mind in the machine: Anthropomorphism increases trust in an autonomous vehicle. Journal of Experimental Social Psychology 52, 113-117 (May 2014). https://doi.org/10.1016/j.jesp.2014.01.005. https://linkinghub.elsevier.com/retrieve/pii/S0022103114000067, reporter: Journal of Experimental Social Psychology

104. Westphal, J.D., Stern, I.: Flattery Will Get You Everywhere (Especially If You Are A Male Caucasian): How Ingratiation, Boardroom Behavior, And Demographic Minority Status Affect Additional Board Appointments at U.S. Companies. Academy of Management Journal 50(2), 267-288 (Apr 2007). https://doi.org/10.5465/amj.2007.24634434, https://journals.aom.org/ doi/abs/10.5465/amj.2007.24634434 number: 2 Reporter: Academy of Management Journal

105. Whitehead, A.: The new fetishism: Western statue devotion and a matter of power. In: Harvey, G. (ed.) The Handbook of Contemporary Animism, pp. 260270. Acumen Publishing (2013), reporter: The Handbook of Contemporary Animism

106. Wong, W.K.W.: Faces on Facebook: A study of self-presentation and social support on Facebook. Undergraduate thesis, City University of Hong Kong, Hong Kong (2012), http://lbms03.cityu.edu.hk/oaps/ss2012-4595-wkw847.pdf 
107. Wu, G., Hu, X., Wu, Y.: Effects of Perceived Interactivity, Perceived Web Assurance and Disposition to Trust on Initial Online Trust. Journal of ComputerMediated Communication 16(1), 1-26 (2010). https://doi.org/10.1111/j.10836101.2010.01528.x https://onlinelibrary.wiley.com/doi/abs/10.1111/j. 1083-6101.2010.01528.x number: 1 Reporter: Journal of Computer-Mediated Communication

108. Zhang, Z., Bickmore, T.W., Paasche-Orlow, M.K.: Perceived organizational affiliation and its effects on patient trust: Role modeling with embodied conversational agents. Patient Education and Counseling 100(9), 1730-1737 (Sep 2017). https://doi.org/10.1016/j.pec.2017.03.017, https://linkinghub.elsevier.com/ retrieve/pii/S0738399117301453 number: 9 Reporter: Patient Education and Counseling 


\section{Appendix}

This table shows the 36 surveyed experiments of verbal machine behavior that correspond with self-presentation strategies: the machine behavior manipulated, the self-presentation strategy corresponding with that behavior, and results, as interpreted by the authors. Further information can be obtained by contacting the authors directly.

\begin{tabular}{|c|c|c|c|c|}
\hline Source & Behavior & Strategy & System/Domain & Results \\
\hline 1 & $\begin{array}{l}\text { appearing } \\
\text { weak }\end{array}$ & Supplication & Furby & reduced response time \\
\hline 2 & $\begin{array}{|ll|}\text { serious } & \text { vs. } \\
\text { playful } & \end{array}$ & $\begin{array}{l}\text { Exemplification } \\
\text { vs. Ingratiation }\end{array}$ & elder assistant & $\begin{array}{l}\text { Ingratiation: increased liking } \\
\text { and perceived intelligence }\end{array}$ \\
\hline 3 & $\begin{array}{l}\text { motivating } \\
\text { messages }\end{array}$ & Exemplification & pedagogical agent & $\begin{array}{l}\text { increased commitment and self- } \\
\text { efficacy }\end{array}$ \\
\hline 5 & empathy & Ingratiation & FitTrack/exercise & $\begin{array}{l}\text { increased liking, engagement, } \\
\text { commitment }\end{array}$ \\
\hline 8 & empathy & Ingratiation & blackjack & $\begin{array}{l}\text { increased perceived caring, lik- } \\
\text { ing, trust }\end{array}$ \\
\hline 14 & $\begin{array}{l}\text { flattery, en- } \\
\text { hancement }\end{array}$ & $\begin{array}{l}\text { Ingratiation vs. } \\
\text { Self-promotion }\end{array}$ & $\begin{array}{l}\text { conversational } \\
\text { agent }\end{array}$ & $\begin{array}{l}\text { Self-promotion: increased per- } \\
\text { ceived power, trust, perceived } \\
\text { expertise; Ingratiation: in- } \\
\text { creased attraction, no increased } \\
\text { liking or trust }\end{array}$ \\
\hline 16 & \begin{tabular}{|l|} 
disclosure, \\
taking inter- \\
est
\end{tabular} & Ingratiation & $\mathrm{NaO}$ & $\begin{array}{l}\text { increased mind, no increased } \\
\text { liking or engagement for per- } \\
\text { sonal vs. factual disclosure }\end{array}$ \\
\hline 18 & empathy & Ingratiation & PR2 & increased trust \\
\hline 19 & $\begin{array}{l}\text { flattery, } \\
\text { praise }\end{array}$ & Ingratiation & questions & $\begin{array}{l}\text { increased enjoyment, engage- } \\
\text { ment, perceived ability }\end{array}$ \\
\hline 21 & $\begin{array}{|ll|}\text { asking } & \text { for } \\
\text { help } & \\
\end{array}$ & Supplication & face recognition & increased engagement \\
\hline 22 & $\begin{array}{l}\text { flattery, } \\
\text { praise }\end{array}$ & Ingratiation & SociBot & $\begin{array}{l}\text { increased liking and trust, re- } \\
\text { duced negative emotion }\end{array}$ \\
\hline 23 & $\begin{array}{l}\text { serious } \\
\text { playful }\end{array}$ & $\begin{array}{l}\text { Exemplification } \\
\text { vs. Ingratiation }\end{array}$ & physical therapy & 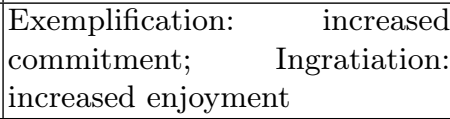 \\
\hline 27 & $\begin{array}{|lr|}\text { error, } & \text { apol- } \\
\text { ogy, } & \text { asking } \\
\text { for } & \text { feedback }\end{array}$ & $\begin{array}{l}\text { Supplication/ } \\
\text { Self-effacement }\end{array}$ & BERT2/cooking & $\begin{array}{l}\text { increased engagement and satis- } \\
\text { faction }\end{array}$ \\
\hline 30 & empathy & Ingratiation & game assistant & reduced frustration \\
\hline 31 & $\begin{array}{l}\text { disclosure, } \\
\text { imitation }\end{array}$ & Ingratiation & $\begin{array}{ll}\text { Virtual Rapport } \\
2.0\end{array}$ & $\begin{array}{l}\text { increased social presence (rap- } \\
\text { port) and naturalness }\end{array}$ \\
\hline 35 & $\begin{array}{l}\text { flattery, } \\
\text { praise }\end{array}$ & Ingratiation & desktop/game & $\begin{array}{l}\text { increased perceived friendliness, } \\
\text { engagement, positive mood, and } \\
\text { perceived ability; reduced con- } \\
\text { fusion }\end{array}$ \\
\hline
\end{tabular}




\begin{tabular}{|c|c|c|c|c|}
\hline 40 & disclosure & Ingratiation & counselor & $\begin{array}{l}\text { increased attraction and co- } \\
\text { presence }\end{array}$ \\
\hline 39 & disclosure & Ingratiation & counselor & $\begin{array}{l}\text { increased engagement (re- } \\
\text { ciprocal disclosure) and rap- } \\
\text { port }\end{array}$ \\
\hline 41 & favors & Ingratiation & desktop & $\begin{array}{l}\text { increased engagement (re- } \\
\text { ciprocal favors) }\end{array}$ \\
\hline 44 & \begin{tabular}{ll|} 
asking & for \\
help &
\end{tabular} & $\begin{array}{l}\text { Self-promotion } \\
\text { vs. Supplication }\end{array}$ & Nao/eyecare & $\begin{array}{l}\text { Self-promotion: increased } \\
\text { perceived intelligence, in- } \\
\text { creased trust, perceived } \\
\text { benefit, attachment, satis- } \\
\text { faction, social presence }\end{array}$ \\
\hline 47 & $\begin{array}{l}\text { empathy, } \\
\text { sympathy }\end{array}$ & Ingratiation & game assistant & increased engagement \\
\hline 52 & flattery & Ingratiation & desktop/trivia & $\begin{array}{lrr}\text { increased attraction } & \text { and } \\
\text { perceived credibility, } & \text { re- } \\
\text { duced conformity } & \\
\end{array}$ \\
\hline [57] & \begin{tabular}{|l|} 
flattery, tak- \\
ing interest, \\
disclosure
\end{tabular} & Ingratiation & $\begin{array}{ll}\text { movie } & \text { recom- } \\
\text { mender } & \end{array}$ & $\begin{array}{l}\text { increased trust and enjoy- } \\
\text { ment, leading to satisfaction } \\
\text { and intention to use }\end{array}$ \\
\hline 59 & empathy & Ingratiation & iCat/chess & $\begin{array}{l}\text { increased perceived friendli- } \\
\text { ness }\end{array}$ \\
\hline 64 & empathy & Ingratiation & iCat/health & $\begin{array}{l}\text { increase perceived friendli- } \\
\text { ness, liking, trust, social en- } \\
\text { gagement }\end{array}$ \\
\hline 69 & disclosure & Ingratiation & circuit building & $\begin{array}{l}\text { increased trust and per- } \\
\text { ceived friendliness }\end{array}$ \\
\hline 73 & errors & $\begin{array}{l}\text { Supplication/Self- } \\
\text { effacement }\end{array}$ & Nao/LEGO & increased liking \\
\hline 75 & disclosure & Ingratiation & desktop & $\begin{array}{l}\text { increased attraction, recip- } \\
\text { rocal disclosure, and general } \\
\text { positive emotion }\end{array}$ \\
\hline 76 & humor & Ingratiation & desktop & $\begin{array}{l}\text { increased liking, reciprocal } \\
\text { humor, perceieved similarity } \\
\text { and cooperation }\end{array}$ \\
\hline 81 & errors & $\begin{array}{l}\text { Supplication/Self- } \\
\text { effacement }\end{array}$ & Daryl & $\begin{array}{l}\text { increased liking, ease, enjoy- } \\
\text { ment, general positive emo- } \\
\text { tion; reduced intelligence, } \\
\text { reliability, security, compe- } \\
\text { tence, and superiority. }\end{array}$ \\
\hline 84 & empathy & Ingratiation & $\begin{array}{l}\text { iCat/language } \\
\text { learning }\end{array}$ & $\begin{array}{l}\text { increased performance and } \\
\text { motivation, reduced physi- } \\
\text { cal proximity }\end{array}$ \\
\hline 87 & disclosure & Ingratiation & Nao (Echo) & $\begin{array}{l}\text { increased perceived warmth } \\
\text { and engagement }\end{array}$ \\
\hline 93 & \begin{tabular}{|l|} 
mutual disclo- \\
sure, $\quad$ taking \\
interest
\end{tabular} & Ingratiation & questions & $\begin{array}{l}\text { increased perceived friendli- } \\
\text { ness }\end{array}$ \\
\hline 94 & agreement & Ingratiation & opinions & $\begin{array}{l}\text { increased reciprocal agree- } \\
\text { ment }\end{array}$ \\
\hline 95 & $\begin{array}{l}\text { playing dumb, } \\
\text { errors }\end{array}$ & Supplication & Nao/vocabulary & increased engagement \\
\hline 108 & 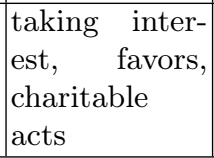 & $\begin{array}{l}\text { Exemplification } \\
+ \text { Ingratiation }\end{array}$ & patient assistant & $\begin{array}{l}\text { Exemplification + Ingratia- } \\
\text { tion: Increased trust, liking, } \\
\text { satisfaction, engagement, } \\
\text { compliance }\end{array}$ \\
\hline
\end{tabular}

